\title{
Website Usability and Cultural Dimensions in Malaysian and Australian Universities
}

\author{
Zanariah Jano ${ }^{1}$, Shuhaida Md. Noor ${ }^{3}$, Rabiah Ahmad ${ }^{2}$, Mohd Shamsuri Md Saad ${ }^{1}$, Rosli Saadan ${ }^{1}$, Mohamad \\ Bokhari $^{1} \&$ Aida Nasirah Abdullah ${ }^{1}$ \\ ${ }^{1}$ Centre for Languages and Human Development, Universiti Teknikal Malaysia Melaka, Melaka, Malaysia \\ ${ }^{2}$ Centre for Research and Innovation, Universiti Teknikal Malaysia Melaka, Melaka, Malaysia \\ ${ }^{3}$ School of Communication, Penang, Malaysia \\ Correspondence: Zanariah Jano, Centre for Languages and Human Development, Universiti Teknikal Malaysia \\ Melaka, Malaysia. Tel: 60-60-17-641-6822. E-mail: zanariahjano@utem.edu.my
}

Received: May 26, 2014 Accepted: July 28, 2014 Online Published: April 2, 2015

doi:10.5539/ass.v11n9p1 URL: http://dx.doi.org/10.5539/ass.v11n9p1

\begin{abstract}
The extent to which web sites in Malaysian and Australian universities comply with usability guidelines of the U.S Department of Health and Human Services was analysed. In order to discover the reasons some websites comply with more guidelines on certain features than others, cultural dimensions in relation to usability of each country were also analysed. Content analysis was employed to measure the usability compliance. Twenty-nine guidelines were selected and twenty university web sites from each country were randomly selected. The findings showed that the trend of standardization was emerging for language and organization category. However, there was also a clear evidence of the need for website designers to consider the impact of local culture as some cultural reflections in terms of high/low context orientation were noted. In terms of culture, unexpectedly, Australian university websites depicted a higher uncertainty avoidance index. This study will be an addition to web design literature and facilitate universities and individuals to develop effective strategies to elevate the image of universities in the global context. Future studies should examine other cultural dimensions such as collectivism versus individualism and power distance. Future studies may also use interview method to gain an in-depth analysis of factors which influence the cultural projection in university websites.
\end{abstract}

Keywords: university, websites, usability, compliance, cultural dimension

\section{Introduction}

\subsection{Background}

As the web is a primary interface between the organisation and its clients and stakeholders, it is high time to ascertain the importance of web design elements to be included in a website. However, a large number of software products or systems with poor usability still exist (Goransson, 2003). Some studies discovered the users' frustration of the website experience because of the poor performance. Elliot \& Fowell (2000) and Lohse \& Spiller (1998) noted customers' frustration with the quality of the websites. Elliot and Fowell (2000) further ascertained that poor attributes in responsiveness of customer service, ease of site navigation, simplicity of check-out process, security and personal information contributed to the frustration. In the domain of higher education, little is known about the use of the Web (Poock \& Lefond, 2003).

Moreover, the cultural dimensions are applied to the selected usability guidelines to hypothesize which guidelines will be favored by each culture. Hofstede's (1980) cultural dimension was applied; Uncertainty Avoidance: "intolerance for uncertainty and ambiguity (Hofstede, 200, p. 401). Hall's (1976) low/high context culture (high context culture convey message in a long-winding and lengthy explanation while low context is the opposite) was also utilized. Australia ranks low in uncertainty avoidance, while Malaysia ranks high in uncertainty avoidance. Hence, Malaysian university websites should employ sites with rules and regulations to ensure that uncertainty level is decreased among users. Hall's (1976) low/high context culture indicates that high context culture convey message in a long-winding and lengthy explanation while low context is the opposite. Hall (1976) divides the context into two; the Eastern and Western. The former embraces the high context realms while the latter the low context's. 
On the whole, the aim of the study is twofold; to identify variances in usability guideline implementation of university web sites in Malaysian and Australian university websites and to analyse cultural causes for the differentiation of usability guidelines. A content analysis is conducted to ascertain the level of usability in both Malaysian and Australian university websites and the cultural dimension as well. The findings of this paper will be an addition to web design literature and facilitate universities and individuals to develop effective strategies to elevate the image of universities in a global context. Knowledge on other cultural preferences of web design will be an asset for web developers. Strategies for the localised versions of web sites will intrigue the stakeholders in the global context. The paper will also explain the validity of both the cultural dimension and cultural categories proposed by Hofstede (1980) and Hall (1976).

\subsection{Relevant Scholarship}

Usability is defined in various ways; "ease of use," - how easily people can use any product's controls or displays such as a tool or computer display (Nielsen, 2002); "how well users can learn and use a product to achieve their goals and how satisfied they are with that process" [U.S Department of Health and Human services (HSS)]; product effectiveness, efficiency, and user satisfaction (ISO, 1998); "the capability to be used by humans easily and effectively" (Shackel, 1991, p. 24). Despite the differences in defining usability, researchers are focusing on the relevance of the human factors for an optimization of interfaces.

Measuring web usability for universities is essential as universities have to compete globally as their brand has become a business asset just like their human, capital and financial resources (Moore, 2004). A number of students accessing the Web is increasing. In 2004, 45 percent of adults and 57 percent of teenagers used the internet to search information about a college or university they were planning of attending (Hitlin \& Rainie, 2005). Bao \& Ellis (2007) conducted a content analysis on 31 universities around the world on features of web standard and usability, using Nielsen \& Tahir's (2002) heuristic guideline and Nichani's (2006) information architecture aspects. They revealed that British and Australian universities were more compliant with Web standards and usability issues. Other universities have various ways in organizing information on their homepage. Kang \& Norton (2006) conducted a content analysis of 129 university web sites in the US in terms of usability, content and interactivity. They noted that most web sites showed excellent performance in projecting usability elements with simplified design, minimal navigation menu, high navigation speed and an inclusion of site map. Consequently, web usability is essential for universities to attract the stakeholders.

Many studies have been carried out to shed light on the effects of cultural differences on web usability as universities are connecting across cultures in the globe. Thus, the emerging issue is whether to adopt standardized or localized versions. The former indicates the features of websites are culturally neutral. Ess and Sudweek (1998) argued that communication would be transparent because the technologies could homogenize the features of design and content of web sites. However, several researchers found the significance of cultural influence in their studies (Alostatht \& Khalfan, 2007; Aydin et al., 2010; Cyr et al., 2005; Simon, 2001). King (2008) studied websites in the UK /Ireland, North America, Central America, West Africa, Pakistan/India and argued that usability itself may also be influenced by context. While some cultures may focus on the performance of usability, others may focus on satisfaction (Caidi \& Komlodi, 2003).

Some usability guidelines which exist in the extant literature are HHS, ISO 9241-151 and Joint information System Committee for higher education (JISC). Bevan (2005) compared and evaluated the three guidelines and concluded that HSS have been widely accepted as "an authoritative source of guidance". Moreover, they have been rated by 8 website designers and 8 usability specialists and ranked for importance based on the rating. (Koyani et al., 2004; Kelly et al., n. d). This transparent methodology provides" confidence in the validity and usefulness of the guidelines (Kelly et al., n. d)".The present study utilizes the guidelines of HHS which feature language and organization category.

Moreover, cultural dimensions were applied to the selected usability guidelines to hypothesize which guidelines would be favored by each culture. Hofstede's (1980) cultural dimensions were applied; Uncertainty Avoidance: "intolerance for uncertainty and ambiguity (Hofstede, 200, p. 401). Hall's (1976) low/high context culture (high context culture convey message in a long-winding and lengthy explanation while low context is the opposite) was also utilized. Hall's (1976) and Hofstede's (1980) cultural dimensions can be used as frameworks for predicting and analyzing intercultural communication online, particularly for "developing the graphical elements of website advertisements, either of consumable goods, such as fast food, or of universities" (Ess \& Sudweeks, 2005). Moreover, guidelines proposed by Marcus and Gould (2000) were used to categorise the usability features to the respective cultural dimension. This study utilises the following research questions and hypotheses 


\subsection{Research Questions and Hypotheses}

\subsubsection{Research Questions}

R1: Do websites of Malaysian and Australian universities differ in complying with the standard usability guidelines in terms of language and organisation category?

R2: Do websites of Malaysian and Australian universities differ in complying with the standard usability guidelines in terms of individual features of language and organisation category?

RQ3: Does culture influence the differentiation of usability guidelines of the university websites in Malaysia and Australia in language and organisation category?

\subsubsection{Hypotheses}

The high/low context category consists of the language dimension. High context (HC) communication is identified by Hall as involving "more of the information in the physical context or internalized in the person" (Hall, 1976, p. 79); greater confidence is placed in the non-verbal aspects of communication than the verbal aspects. Communication in LC cultures is described by Hall as "just the opposite [of HC communication]; i.e. the mass of information is vested in the explicit code" (Hall, 1976, p. 79). In contrast, people from low context (LC) communication style communicate how they feel directly whereas a person from a HC culture will set the context and the setting and let the message evolve without referring to the problem directly.

H3a: Malaysian universities, which represent high context culture, use more number of words and sentences than do Australian university websites.

The uncertainty avoidance index includes features from organisation category. Uncertainty avoidance refers to the extent to which a culture seeks to reduce risk typically favouring rules and structure. Websites with high uncertainty avoidance focus on the deterrence of errors, few options, and a navigation features which prevents users from getting lost in the site (Hofstede, 1980). Websites with low uncertainty avoidance promote exploration and provide many options.

H3b: Malaysian universities with a higher uncertainty avoidance index will have more limited homepage length than Australian university websites with a lower uncertainty avoidance index.

H3c: Malaysian universities with a higher uncertainty avoidance index will use site maps more than Australian university websites with a lower uncertainty avoidance index.

\section{Method}

This section illustrates the content analysis method, samples, procedure, and sampling procedure.

\subsection{Content Analysis of Websites}

The complex mix of old and new features of websites makes the medium a challenge for web content analysts (Newhagen \& Rafaeli, 1996). Studying the content of websites is academically crucial but also challenging and interesting as it is an effective method for discerning patterns and themes in textual and graphic data. Websites are used to educate people, change people's minds, or compel action. As argued by Scharl (2006), studying and analyzing web content helps us to see what some real website producers and developers consider while making their websites.

Content analysis is chosen because it is used in a variety of fields, such as marketing and media studies, literature, sociology, psychology, cultural studies, and educational research. Content analysis is also applied as it is an appropriate method for answering most of the research questions in this study. Meanwhile, the quantitative method will be used in this thesis to explore what Sinha et al. (2001) suggest, that a subjective website experience can be quantified in terms of more specific dimensions of website quality such as content, interactivity, navigation, etc., in a reliable way. The measure is quantified through a descriptive analysis.

Quantitative research involves an attempt to analyze human behavior in terms of statistics (Horna, 1994). Charles R. Wrights states that content analysis is a systematic technique which classifies and describes communication content according to certain predetermined categories (see Berger, 2000, p. 173). Technical objectivity requirement, stated by Wright entails that the 'categories of classification and analysis be clearly and operationally defined '(see Berger, 2000, p. 173). Leeuwen and Jewitt (2001, p. 14) assert that visual content analysis is a systematic, observational method used for testing hypotheses about the ways in which the media represent people, events and situation. Content analysis provides a quantified dimensional description of fields of representation. The methodology can be used to provide a background 'map' of a domain of visual 
representation (Leeuwen \& Jewitt, 2001, p. 27). A quantitative method for the content analysis of the websites was applied to investigate the availability of the units of analysis coded.

\subsection{Samples}

20 websites from Malaysian and Australian universities were selected. In conducting this study, the websites of universities in Malaysia and Australia are chosen because Australian universities may provide interesting and diversified ways of designing their websites because of the advanced state of the country in aspects and the use of the ICT. The results of this study are expected to show significant differences in the usability and interactivity dimensions of Websites across these universities. In terms of cultural orientation, these countries are most likely to show observable cultural differences as they represent two distinct cultures (Hofstede, 1980; Hall, 1976). The samples were taken from the database of the Ministry of Education of Australia and the Ministry of Higher Education of Malaysia.

\subsection{Procedure}

The researcher chose the list of universities both in Malaysia and Australia. The universities were coded and given number in the Microsoft Excel spreadsheet. Then, the RANDBETWEEN function was used to randomly select 20 universities from each country. The second stage of selection involved an elimination of universities that did not fulfil the criteria. The universities must possess the following criteria:

- The web sites are good and well developed. They are not under construction.

- The web sites can be searched via the Yahoo and Google Search Engines.

- The web sites must have at least one type of social networking sites (Blog, Flickr, Face book).

The university websites were filtered and 40 university websites from Malaysia and Australia were selected. Next, two coders who were fluent in both Malay and English analysed the website based on the given criteria. The coding process was done using SPSS application like the independent sample t-test to discover the significant differences among universities in Malaysia and Australia on the usability features. The next stage involved two coders namely Coder A and Coder B for the coding purposes. They were post graduate students at the Universiti Teknikal Malaysia Melaka, and they were trained by the researcher specifically for the purpose of this thesis. They were paid for incentives. To proceed with the coding tasks, all the coders were trained to code websites not included in the main study. Coder A and B eventually coded all the variables. The data were compared and inventory coding was reconciled. Then a check-list was produced and named as an ' Inventory Coding"

For the next step, Coder A and B, independently, applied the coding whilst re-evaluating the websites. During the re-evaluation process, some modifications and adjustments whereby some minor changes were applied to the checklist as and where necessary, and finally the final inventory coding was produced. Several steps were applied for the content analysis of websites in this study as shown in Figure 1. The analysis features the progression from the homepage to the subsequent page.

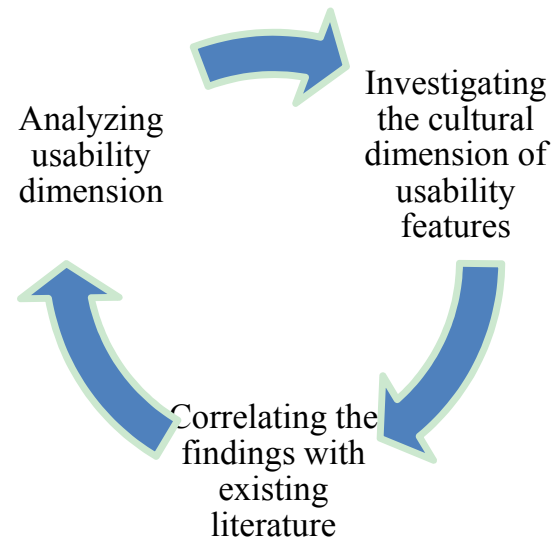

Figure 1. Procedure for analysis 


\subsection{Unit of Analysis}

Many researchers have not always agree on how deep in a site one must go to test interactivity. Some suggest that only homepages should be analyzed and others feel that the study should focus on other levels as well. Hwang et al. (2002 and Paul (2001) analyze the homepages and others focus on two or more levels (Okazaki \& Rivas, 2002). McMillan et al. (2008) propose two levels, the home page and the level one to measure interactivity. She notes that fewer features are found at home page and there is a positive correlation between homepage and level one. Interestingly, more research should be conducted to gain more insights into the layers of websites which promote interactivity.

The homepage, which is located at the very top level, is a flagship of the site, and normally has different designing elements compared to other pages, such as a larger logo and a more prominent placement of the company name or site name, and a more prominent placement of the company name or site name (Nielsen, 2000). Ivory (2003) and Nielsen (2000) reveal that homepages have measurably different characteristics than the other pages. Symonenko $(2006,2007)$ stresses that corporate homepages often have links to "About", "Products/Services", and "Contact" for content categories in which the homepages direct their visitors. The information or the content on Level one, two and three of the websites are geared towards the respective topics or audiences (Symonenko, 2006). Three to five level hierarchy is ideal for web content analysis (Brinck et al., 2001; Larson \& Szerwinski, 1998; McCracken \& Wolfe, 2004; Morville \& Rosenfeld, 2002; Symonenko, 2006, 2007). This study, hence, analyses all the four levels of sites identified on websites of Malaysian and Australia based on this rationale.

\subsection{Data Collection}

\subsubsection{Analysing Level of Usability}

The data for this analysis was collected from 20 websites of Malaysian and 20 Australian universities from December 6 to December 17, 2010. A coding instrument was developed to capture the level of usability of university websites in the Malaysian and Australian university websites. To address questions related to the level of usability of university websites, this study analyzed the characteristics of university websites on the dimensions of language and organisation. Using the HSS schemes, language consists of make action sequences clear, avoid jargon, use mixed case with prose, limit the number of words and sentences and, compose sentences in active voice while organisation consists of features like use a fluid layout, eliminate horizontal scrolling, align items on a page, "link to the homepage from any other page on the web site, limit homepage length, place important items at top centre, enable cross-browser compatibility, place primary navigation menus in the left panel, use site maps, provide feedback on user's location, provide a search option on each page, maintain design consistency, show author credentials and contact information, provide printing option, use a clickable 'list of contents on long pages and include hints to improve search performance.

The coding process was done using the independent sample t-test to discover the significant differences among universities in Malaysia and Australia on the interactivity and usability features. Initially, the score of the interactivity and usability categories were compared by an independent sample test (T-test). Then, the similar test was applied to compare the difference among the individual features in each category. The findings were reported in three sequence; overall features of category, university websites' performance for Malaysia and Australia and individual feature of each category. Specifically, a high level of usability is characterized by the score of the high end (5 or 7), moderate to well (3-4) and poor (1-2).

\subsubsection{Analyzing Level of Cultural Dimension}

Then, the categories and features which showed significant difference were assessed in relation to cultural dimension. The significant features of interactivity and usability were assigned to respective cultural category. T-test was administered to find the significant difference of cultural values between Malaysian and Australian university websites. Predictor variables used were high/low context in terms of language (limit the number of words and sentences) and uncertainty avoidance index (limit homepage length and use sitemap).

\section{Findings and Discussion}

\subsection{Usability}

R1: Do websites of Malaysian and Australian universities differ in complying with the standard usability guidelines in terms of language and organisation category?

On the whole, there was significant difference between websites of Malaysian $(\mathrm{M}=4.6, \mathrm{SD}=0.47)$ and Australian universities $(\mathrm{M}=4.9, \mathrm{SD}=0.24)$ in complying with the standard usability guidelines in terms of language category 
with $t(28.3)=-2.82, p<0.05$. However, there was no significant difference between websites of Malaysian universities $(\mathrm{M}=3.8, \mathrm{SD}=0.30)$ and Australian universities $\mathrm{M}=3.9, \mathrm{SD}=0.41$ in complying to the standard usability guidelines in terms of organization with $t(38)=-1.15, p>0.05$. Table 1 demonstrates the score of usability index for both Malaysian and Australian university websites in terms of language category.

Table 1. t-test score for language and organization category

\begin{tabular}{cccccccc}
\hline Category & \multicolumn{2}{c}{ Malaysia } & \multicolumn{2}{c}{ Australia } & & & \\
\hline & M & SD & M & SD & t & df & Sig (2-tailed) \\
\hline Language & 4.6 & 0.47 & 4.9 & 0.24 & -2.82 & 28.290 & .009 \\
Organization & 3.8 & 0.3 & 3.9 & 0.41 & -1.15 & 38 & 0.26 \\
\hline
\end{tabular}

R2: Do websites of Malaysian and Australian universities differ in complying with the standard usability guidelines in terms of individual features of language and organisation category?

In terms of language, only one feature, Limit the number of words and sentences, showed significant difference; Websites of Malaysian universities features $\mathrm{M}=3.1, \mathrm{SD}=1.93$ and $\mathrm{M}=4,8, \mathrm{SD}=0.79$ for websites of Australian universities with $\mathrm{t}(25.1)=-3.64, \mathrm{p}<0.05$. Other features fell within the range of mean of 4.7 and above while Use mixed case with prose and Compose sentences in active voice scored a mean of 5.00 which indicated a full compliance. Table 2 illustrates the t-test score for individual features in language category.

Table 2. t-test score for individual features in Language category

\begin{tabular}{lcccccccc}
\hline Category & Feature & Malaysia & Australia & & \\
\hline & & M & SD & M & SD & t & df & Sig (2-tailed) \\
\hline \multirow{2}{*}{ Language } & Make action sequences clear & 4.9 & 0.44 & 4.7 & 0.97 & 0.83 & 38 & 0.41 \\
& Avoid jargon & 4.9 & 0.67 & 5 & 0 & -1.00 & 19 & 0.33 \\
& Limit the number of words and sentences & 3.1 & 1.93 & 4.7 & 0.79 & -3.64 & 25.13 & 0.00 \\
\hline
\end{tabular}

In terms of organization, two features showed significant difference for Organization category; Limit homepage length: websites of Malaysian universities $(\mathrm{M}=2.2, \mathrm{SD}=1.74)$ and Australian universities $(\mathrm{M}=3.6, \mathrm{SD}=1.96)$ with $t(38)=-2.39, p<0.05$, Use site maps: websites of Malaysian universities $(\mathrm{M}=4.4, \mathrm{SD}=1.31)$ and Australian universities $(\mathrm{M}=3.3, \mathrm{SD}=1.94$ with $t(33.4)=2.19, p<0.05$. On the contrary, fourteen features indicated no significant difference in complying with the usability guidelines. Table 3 features the score.

Table 3. t-test score for individual features in organization category

\begin{tabular}{|c|c|c|c|c|c|c|c|c|}
\hline \multirow[t]{2}{*}{ Category } & \multirow[t]{2}{*}{ Feature } & \multicolumn{4}{|c|}{ Malaysia Australia } & \multirow[b]{2}{*}{ t } & \multirow[b]{2}{*}{ df } & \multirow[b]{2}{*}{ Sig (2-tailed) } \\
\hline & & M & SD & M & SD & & & \\
\hline \multirow{16}{*}{ Organisation } & Eliminate horizontal scrolling & 2.7 & 1.93 & 3 & 2.05 & -0.56 & 38 & 0.58 \\
\hline & Align items on a page & 5 & 0 & 4.9 & 0.22 & 1.00 & 19 & 0.33 \\
\hline & $\begin{array}{l}\text { Link to the homepage from any other page on } \\
\text { the web site }\end{array}$ & 4.7 & 0.97 & 4.9 & 0.44 & -0.83 & 38 & 0.41 \\
\hline & Limit homepage length & 2.2 & 1.74 & 3.6 & 1.96 & -2.39 & 38 & 0.02 \\
\hline & Place important items at top centre & 4.6 & 1.15 & 4.9 & 0.22 & -1.53 & 38 & 0.13 \\
\hline & Place primary navigation menus in the left panel & 3.9 & 1.77 & 4.8 & 0.89 & -2.03 & 28.1 & 0.05 \\
\hline & Use site maps & 4.4 & 1.31 & 3.3 & 1.94 & 2.19 & 33.4 & 0.04 \\
\hline & Provide a feedback on user's location & 4 & 1.34 & 4.6 & 0.94 & -1.64 & 34.1 & 0.11 \\
\hline & Provide a search option on each page & 3.9 & 1.7 & 4.7 & 0.92 & -1.73 & 29.3 & 0.09 \\
\hline & Maintain design consistency & 5 & 0 & 4.9 & 0.22 & 1 & 19 & 0.33 \\
\hline & $\begin{array}{l}\text { Show authors credentials and contact } \\
\text { information }\end{array}$ & 4.8 & 0.61 & 4.3 & 1.39 & 1.33 & 38 & 0.19 \\
\hline & Provide printing option & 2.9 & 1.99 & 2 & 1.76 & 1.43 & 38 & 0.16 \\
\hline & Use a clickable "list of contents" on long pages & 1.2 & 0.89 & 1.6 & 1.35 & -0.96 & 32.9 & 0.34 \\
\hline & Include hints to improve search performance & 1.7 & 1.49 & 1.4 & 1.23 & 0.69 & 36.7 & 0.49 \\
\hline & Use a fluid layout & 5 & 0 & 5 & 0 & & & \\
\hline & Enable cross browser compatibility & 5 & 0 & 5 & 0 & \multicolumn{3}{|c|}{ Full compliance } \\
\hline
\end{tabular}


A good rating was shown for language category for websites of both countries; 4 out of 5 features of language showed compliance to standard usability guidelines. In terms of organization; two features had full score ( $\mathrm{M}=$ 5.00) for compliance with usability guidelines. This agrees with findings of King (2008) which found that use a fluid layout is passed by nearly all websites in his study. On the other hand, the grey areas include Limit homepage length, Eliminate horizontal scrolling and Provide printing options which scored a poor to moderate rating for both websites of Malaysian and Australian universities. This is contrary to King's (2008) findings who discovered that eliminate horizontal scrolling was adhered by most websites.

Overall, interestingly almost all features of language and nine features of organization category are rated from good to excellent which shows that websites of both universities are heading towards standardization. This is contrary to Bao and Ellis's (2007) findings which discovered that British and Australian universities are more compliant with Web standards and usability issues than others around the world.

\subsection{Usability and Cultural Dimension}

Based on the findings, one language and two organization features showed significant difference. Table 4 illustrates the score of usability features in relation to cultural dimension.

Table 4. Cultural dimension and respective usability features

\begin{tabular}{|c|c|c|c|c|c|c|c|c|}
\hline \multirow[t]{2}{*}{ Cultural dimension } & \multirow[t]{2}{*}{ Feature } & \multicolumn{4}{|c|}{ Malaysia Australia } & \multirow[b]{2}{*}{$\mathbf{t}$} & \multirow[b]{2}{*}{ df } & \multirow[b]{2}{*}{ Sig (2-tailed) } \\
\hline & & M & SD & $\mathbf{M}$ & SD & & & \\
\hline Low/high context & $\begin{array}{l}\text { Limit the number of words and } \\
\text { sentences }\end{array}$ & 3.1 & 1.93 & 4.7 & 0.79 & -3.64 & 25.13 & 0.00 \\
\hline $\begin{array}{l}\text { Uncertainty avoidance } \\
\text { index }\end{array}$ & $\begin{array}{c}\text { Limit homepage length } \\
\text { Use site maps }\end{array}$ & $\begin{array}{l}2.2 \\
4.4\end{array}$ & $\begin{array}{l}1.74 \\
1.31\end{array}$ & $\begin{array}{l}3.6 \\
3.3\end{array}$ & $\begin{array}{l}1.96 \\
1.94\end{array}$ & $\begin{array}{r}-2.39 \\
2.19\end{array}$ & $\begin{array}{c}38 \\
334\end{array}$ & $\begin{array}{l}0.02 \\
0.04\end{array}$ \\
\hline
\end{tabular}

Thus, according to categorization by Marcus and Gould (2000). three hypotheses were devised as follows:

RQ3: Does culture influence the differentiation of usability guidelines of the university websites in Malaysia and Australia in Language and organisation category?

H3a: Malaysian universities, which represent high context culture, use more number of words and sentences than do Australian university websites.

H3b: Malaysian universities with a higher uncertainty avoidance index will have more limited homepage length than Australian university websites with a lower uncertainty avoidance index.

H3c: Malaysian universities with a higher uncertainty avoidance index will use site maps more than Australian university websites with a lower uncertainty avoidance index.

In terms of language, Limit the number of words and sentences for websites of Malaysian universities features $\mathrm{M}=3.1, \mathrm{SD}=1.93$ and $\mathrm{M}=4.8, \mathrm{SD}=0.79$ for websites of Australian universities with $\mathrm{t}(25.1)=-3.64, \mathrm{p}<0.05$. Hence, H3a is supported. The finding is as expected by Hall (1976) in his low/high context dimension; the Eastern culture of high context orientation tends to use more words and sentences to convey message. This also confirms the results by Aydin (2010) who stated that Turkish websites displayed higher context oriented features. Organization wise, two results are as follows:

- The score for Limit homepage length for websites of Malaysian universities was $(\mathrm{M}=2.2, \mathrm{SD}=1.74)$ and Australian universities $(\mathrm{M}=3.6, \mathrm{SD}=1.96)$ with $t(38)=-2.39, p<0.05$. Websites of Malaysian universities had more homepage length than websites of Australian universities. Hence $3 \mathrm{~b}$ is not supported.

- The score for Use site map for websites of Malaysian universities was $(\mathrm{M}=4.4, \mathrm{SD}=1.31)$ and Australian universities $(\mathrm{M}=3.3, \mathrm{SD}=1.94$ with $t(33.4)=2.19, p<0.05$. This showed that websites of Malaysian universities featured more site maps than websites of Australian universities. Thus, H3c is supported.

As a result, only one hypothesis was supported for organization category; Use of site map (websites of Malaysian universities $(\mathrm{M}=4.4, \mathrm{SD}=1.31)$ and Australian universities $(\mathrm{M}=3.3, \mathrm{SD}=1.94$ with $t(33.4)=2.19, p<$ 0.05). Interestingly, Australian university websites showed a higher uncertainty avoidance index. This is similar to a study by Aydin (2010) which found that US websites demonstrated more uncertainty avoidance features compared to Turkish websites. Similarly, Callahan (2005) also found that all websites features correlated with Hofstede's (1980) index except for the Uncertainty Avoidance measures. Does this mean that Western universities have internationalization strategies to attract students from the East or as argued by Callahan (2005), whether the aspects of uncertainty avoidance index of Hofstede should be revised? 


\section{Conclusions}

Overall, in terms of usability, almost all features of language and nine features of organization category are rated from good to excellent which shows that websites of both universities are heading towards standardization. However, there is also a clear evidence of the need for website designers to consider the impact of local culture as cultural reflection is observed in terms of high/low context orientation. In terms of culture, unexpectedly, Western university websites such as Australia depict higher uncertainty avoidance index. Thus, the issue is whether the lower uncertainty avoidance countries tend to absorb the values of the high indexed ones for the purpose of internationalization or the latter may favor cultural dimensions of the lower indexed ones. Cyr et al. (2005) reflect that homogenization of web design across the world may have occurred because web sites adopt the design conventions of similar web sites across the globe. Indeed, the two opposing trends, standardization and localization exist in web design realm and are continuously evolving. The intricate interplay of these trends is worthy of web designers' attention.

The study is limited in terms of the samples, scope of cultural dimensions and genre used which prevent the generalization of the findings. More university websites from other countries should be included to obtain more understanding of how they comply with the usability compliance. Future studies will examine the other cultural dimensions such as collectivism versus individualism and power distance. Future studies may also use interview method to gain an in-depth analysis of factors that contribute to the standardization of usability elements and projection of cultural values in university websites. This study has pragmatic implications for universities in both developed and developing countries for internationalization strategies.

\section{Acknowledgements}

This work was supported in part by a research fund of Ministry of Higher Education, Malaysia.

\section{References}

Alostath, J. M., \& Khalfan, A. M. (2007). In Springer-Verlag, A. N. (Ed.), Cross-Use: Cross-Cultural Usability User Evaluation-In-Context. Usability and Internationalization. Berlin. http://dx.doi.org/10.1007/978-3540-73287-7_28

Aydin, G. K. (2010). Cultural Variability in Web Content: A Comparative Analysis of American and Turkish Websites. International Business Research, 3(1), 97-103. http://dx.doi.org/10.5539/ibr.v3n1p97

Bao, T. Q., \& Ellis, A. (2007). Assessing University Homepages from Web standard and usability perspectives. Retrieved from http://ausweb.scu.edu.au/aw07/papers/refereed/tran/paper.html

Berger, A. A. (2000). Media and Communication Research Methods: An Introduction to Qualitative and Quantitative Approaches. London: Sage.

Bevan, N. (2005). Guidelines and Standards for Web Usability. In Proceedings of HCI International. Las Vegas, Nevada: Lawrence Erlbaum.

Brinck, T., Gergle, D., \& Wood, S. (2001). Usability for the Web: Designing Web sites that work. San Francisco: Morgan Kaufmann.

Caidi, N., \& Komlodi, A. (2003). Digital libraries across cultures: Design and usability issues. SIGIR Forum, 37, 52-54.

Cyr, D., Bonanni, C., Bowes, J., \& Ilsever, J. (2005). Beyond trust: Web site design preferences across cultures. Journal of Global Information Management, 13(4), 25-54. http://dx.doi.org/ 10.4018/jgim.2005100102

Elliot, S., \& Fowell, S. (2000). Expectations versus reality: A snapshot of consumer experiences with internet retailing. International Journal of Information Management, 20, 323-336. http://dx.doi.org/10.1016/S02684012(00)00026-8

Ess, C., \& Sudweeks, F. (1998). Computer-mediated communication or culturally-mediated computing? Challenging assumptions of the electronic global village. Electronic Journal of Communication, 8(3\&4). Retrieved from http://www.cios.org/www/ejcmain.htm

Ess, C., \& Sudweeks, F. (2005). Culture and Computer-Mediated Communication: Toward New Understandings. Journal of Computer-Mediated Communication, 11(1). http://dx.doi.org/10.1111/j.1083-6101.2006.00009.x

Goransson, B., Gulliksen, J., \& Boivie, I. (2003). The usability design process - integrating user- centered systems design in the software development process. Software Process Improvement and Practice, 8(2), 111-131. http://dx.doi.org/ 10.1002/spip.174 
Hall, E. T. (1976). Beyond Culture. New York. Anchor Press-Doubleday.

Hitlin, P., \& Rainie, L (2005). Teens, technology, and school. In Pew Internet \& American Life Project. Retrieved from http://www.pewinternet.org/pdfs/PIP_Internet_and_schools_05.pdf

Hofstede, G. (1980). Culture's Consequences: International Differences in Work-Related Values. Newbury Park: Sage.

Horna, J. (1994). The Study of Leisure. Oxford: Oxford University Press.

Hwang, Y., Seo, E., \& Kim, J. (2002). WebAlchemist: A Structure- Aware Web Transcoding System for Mobile Devices. In Mobile Search Workshop. Honolulu, Hawai.

International Organization for Standardization ISO 9241-11: Part 11. Guidance on Usability Retrieved from http://www.userfocus.co.uk/resources/iso9241/part11.html

Ivory. (2003). Web site designs: Influence of designers expertise and design constraints. International Journal of Human-Computer Studies, 58(1), 57-87. http://dx.doi.org/ 10.1016/S1071-5819(02)00126-X

Johnson, J. (2007). GUI Bloopers: Common Interface Blunders and How to Avoid Them. In Software Test \& Performance, 4(12), 22-26.

Kang, S., \& Norton, H. E. (2006). Colleges and Universities use of the World Wide Web: A public relations tool for school excellence in the digital age. Public relation, 32(4), 426-428.

Kelly., Sloan, D., Phipps, L., \& Petrie, H. (n. d.). Forcing standardisation or Accommodating Diversity? A framework for Applying the WCAG in the Real World. Retrieved from http://www.scribd.com/doc/13033/ Forcing-Standardization-or-Accommodating-Diversity-A-Framework-for-Applying-the-WCAG-in-the-Real -World. http://dx.doi.org/ 10.1145/1061811.1061820

King, J. P. (2008). Web Usability on an International Scale: A Content Analysis. A Master's Paper for the M.S. in I.S degree. University of North Carolina.

Koyani, S. J., Bailey, R. W., \& Nall, J. R. (2004). Research-Based Web Design \& Usability Guidelines. Retrieved from http://www.usability.gov/guidelines/guidelines_book.pdf

Larson, K., \& Czerwinski, M. (1998). Web page design: implications of memory,structure, and scent for information retrieval. Paper presented at the CHI 98 Human Factors in Computing Systems, Los Angeles.

Leeuwen, T. V., \& Jewitt, C. (2001). Handbook of visual analysis. London: Sage.

Lohse, G. L., \& Spiller, P. (1998). Electronic shopping: The effect of customer interfaces on traffic and sales. Communications of the ACM, 41, 81-87.

Marcus, A., \& Gould, E. W. (2000). Crosscurrents: Cultural Dimensions and Global Web User-Interface Design. Interactions, 7(4), 32-46. http://dx.doi.org/10.1145/345190.345238

McCracken, D. D., \& Wolfe, R. J. (2004). User-centered website development: A human-computer interaction approach. Upper Saddle River, NJ: Pearson Education, Inc.

McMillan, J., Hoy, G., Kim, J., \& McMahan, C. (2008). A Multifaceted Tool for a Complex Phenomenon: Coding Web-based Interactivity as Technologies for Interaction Evolve. Journal of Computer-Mediated Communication, 13(4), 794- 826.

Moore, M. G. (2004). Innovation and change. The American Journal of Distance Education, 1(4), 195-198.

Morville, P., \& Rosenfeld, L. (2002). Information Architecture for the World Wide Web: Designing Large-Scale Web Sites. CA: O'Relly Media Inc.

Newhagen, J. E., \& Rafaeli, S. (1996). Why communication researchers should study the Internet: A dialogue. Journal of Communication, 46(1), 4-13.

Nichani, M. (2006). The Changing Face of University Websites. Retrieved from http://www.pebbleroad.com/ article/the_changing_face_of_university_websites/

Nielsen, J. (2000). Designing web usability. Indianapolis, New Riders Publishing.

Nielsen, J. (2002). Coordinating User Interfaces for Consistency. San Francisco, Morgan Kaufman.

Nielsen, J., \& Tahir, M. (2002). Homepage Usability: 50 Websites Deconstructed. Indianapolis, IN,New Riders Publishing.

Okazaki, S., \& Rivas, J. A. (2002). A Content Analysis of multinationals' Web communication strategies: 
Cross-cultural research framework and pre-testing. Internet Research: Electronic Networking Applications and Policy, 12(5), 380-390.

Paul, M. J. (2001). Interactive disaster communication on the Internet: A content analysis of sixty - four disaster relief home pages. Journalism \& mass Communication Quarterly, 78(4), 739-753.

Poock, M. C., \& Lefond, D. (2003). Characteristics of effective graduate school Web sites: Implications for the recruitment of graduate students. College and University Journal, 78(3), 15-19.

Poock, M., \& Lefond, D. (2001). How college-bound prospects perceive university websites: findings, implications and turning browsers into application. College and University Journal, 78(3), 12-21.

Scharl, A. (2006). Catalyzing environmental communication through evolving internet technology. Environmental Communication Yearbook, 3, 235-242.

Shackel, B. (1991). BLEND-9: Overview and appraisal (British Library Research Paper 82). London: British Library.

Simon, S. J. (2001). The impact of culture and gender on web sites: an empirical. International Journal of Electronic Commerce, 2(2), 29-56.

Sinha, R., Hearst, M., \& Ivory, M. (2001). Content or graphics? An empirical analysis of criteria for award-winning websites. Proceedings of the 7th Conference on Human Factors and the Web. Retrieved from http://webtango.berkely.edu/papers/hwf01/hwf01.htm

Spool, J. M., Scanlon, T., Schroeder, W., Snyder, C., \& De Angelo, T. (1997). Web Site Usability: A Designer's Guide. North Andover, MA: User Interface.

Stengers, H. (2004). Localization of Web Sites: Is there Still a Need for It? International Workshop on WebEnginering (Hypertext 2004 Conference). Santa Cruz. Retrieved from http://wsdm.vub.ac.be/Download/Papers/WISDOM/LocalizationOfWebSites.pdf

Symonenko, S. (2006). Exploring patterns in website content structure. Retrieved from http://www.iusummit.org/2006/files/177_Presentation_Desc.pdf

\section{Copyrights}

Copyright for this article is retained by the author(s), with first publication rights granted to the journal.

This is an open-access article distributed under the terms and conditions of the Creative Commons Attribution license (http://creativecommons.org/licenses/by/3.0/). 